NBER WORKING PAPER SERIES

\title{
WHO BENEFITS FROM NEW MEDICAL TECHNOLOGIES? ESTIMATES OF CONSUMER AND PRODUCER SURPLUSES FOR HIV/AIDS DRUGS
}

\author{
Tomas J. Philipson \\ Anupam B. Jena \\ Working Paper 11810 \\ http://www.nber.org/papers/w11810 \\ NATIONAL BUREAU OF ECONOMIC RESEARCH \\ 1050 Massachusetts Avenue \\ Cambridge, MA 02138 \\ December 2005
}

\begin{abstract}
Corresponding author: t-philipson@uchicago.edu. We are thankful for comments from participants at the NIH-Director conference Biomedical Innovation and the Economy held in Bethesda, June 1, 2005. Philipson is thankful for financial support from The Milken Institute, Santa Monica, CA. Jena received fellowship support from the NIH through the University of Chicago Medical Scientist Training Program. We are thankful for comments and help from Gary Becker, Darius Lakdawalla, Lisa Lee (CDC), Michael Campsmith (CDC), Ruigang Song (CDC), and Jennifer Kates (Kaiser Family Foundation). The views expressed herein are those of the author(s) and do not necessarily reflect the views of the National Bureau of Economic Research.
\end{abstract}

(C2005 by Tomas J. Philipson and Anupam B. Jena. All rights reserved. Short sections of text, not to exceed two paragraphs, may be quoted without explicit permission provided that full credit, including @ $)$ notice, is given to the source. 
Who Benefits from New Medical Technologies? Estimates of Consumer and Producer Surpluses for HIV/AIDS Drugs

Tomas J. Philipson and Anupam B. Jena

NBER Working Paper No. 11810

December 2005

JEL No. I1

\section{$\underline{\text { ABSTRACT }}$}

The social value of an innovation is comprised of the value to consumers and the value to innovators. We estimate that for the HIV/AIDS therapies that entered the market from the late 1980's onwards, innovators appropriated only $5 \%$ of the social surplus arising from these new technologies. Despite the high annual costs of these drugs to patients, the low share of social surplus going to innovators raises concerns about advocating cost-effectiveness criteria that would further reduce this share, and hence further reduce incentives for innovation.

Tomas J. Philipson

Graduate School of Public Policy Studies

The University of Chicago

1155 E 60th Street

Chicago, IL 60637

and NBER

t-philipson@uchicago.edu

Anupam B. Jena

Department of Economics

The University of Chicago

1126 E 59th Street

Chicago, IL 60637

ajena@uchicago.edu 


\section{Section 1: Introduction}

The value of a new technology may be divided between consumers, whose willingness to pay may exceed the price paid, and producers or innovators, whose costs may be lower than the price charged. Consumer surplus is central to static efficiency after an innovation has been discovered, while producer surplus, which forms the incentive for firms to engage in costly $R \& D$ to bring an innovation to market, is central to dynamic efficiency. Therefore, understanding the degree to which innovation benefits consumers versus producers is important for policies aimed at trading off the two forms of efficiency, such as intellectual property and $\mathrm{R} \& \mathrm{D}$ policies.

However, empirical evidence on the division of social surplus arising from new health care technologies is very scarce or non-existent. To begin to remedy this lack of knowledge, this paper investigates this issue for a major breakthrough in medicine-the new drugs to treat HIV/AIDS that came on the market after the late 1980's. HIV/AIDS is an important case to consider in and of itself, partly because it is perhaps the major disease targeted by public sector R\&D in the US. ${ }^{2}$ For the new HIV drugs that came about during this period, our major finding is that innovators captured only 5\% of the social surplus arising from these new technologies. More precisely, consumer and producer surplus from these drugs amounted to roughly $\$ 1.33$ trillion and $\$ 63$ billion, respectively. We argue that if the new HIV/AIDS therapies are representative of other technologies, the lack of appropriation of social surplus by innovators has strong policy implications for how to adopt and evaluate new health care technologies. Despite the high prices of many therapies such as the new HIV drugs, patients and health plans are getting too good a deal in the short run which, of course, hurts them in the long run by insufficient $R \& D{ }^{3}$

The low share of appropriation by innovators can be understood by some simple back-of-the-envelope calculations. For the size of the consumer surplus, consider the 1.5 million US citizens who have been infected by HIV since the start of the epidemic, some of whom died before drug therapy became available and some of whom lived until or contracted HIV after the breakthrough drugs entered the market in the mid 1990's. Averaging across all such cohorts, the gain

\footnotetext{
${ }^{2}$ Public R\&D on HIV/AIDS was roughly \$2 billion in 2000. Health, in general, is among the three leading industries into which the government allocates its R\&D, the other two being defense and aero-space. The National Institutes of Health (NIH) is responsible for allocating the vast majority of the public R\&D dollar-in 1999, NIH funding accounted for nearly $81 \%$ of public spending on health R\&D. Of the $\$ 13.9$ billion that the NIH spent on research in 1999 , nearly $\$ 1.8$ billion (13\%) was spent on HIV/AIDS (Health, United States, 2002).

${ }^{3}$ The inefficiency typically associated with non-appropriation is the classic one discussed in the literature. See, for example, Arrow (1961), Tirole (1988), and more recently, Philipson and Jena (2005).
} 
in life-expectancy has been at least 5 years. With a low value of a life-year of $\$ 100,000$, the added survival has been worth more than $\$ 500$ thousand per individual and $\$ 750$ billion in aggregate. This figure, of course, does not include the benefit to those individuals who become infected with HIV in later years but can benefit from drugs introduced to date-doing so, while assuming current incidence rates persist in the future, raises the total consumer value of these drugs above $\$ 1$ trillion. ${ }^{4}$

For the size of the producer surplus, consider that sales of HIV/AIDS drugs have grown from $\$ 1$ billion to $\$ 4$ billion annually since the breakthrough drugs came on the market in 1996. From these revenues, one can compute a present value of sales of $\$ 74$ billion assuming that drugs sell at current levels in the future. We can then subtract the variable costs of production, which are approximated to be $15 \%$ of revenues based on estimates of markups stemming from differences in drug prices pre- and post patent expiration.

This paper is related to several strands of other work. Our finding of a low degree of surplus appropriation by innovators of HIV/AIDS drugs relates to an existing literature outside of health economics on the general inability of innovators to capture the social value of their inventions. ${ }^{5}$ It also relates to a vast and growing literature on cost-effectiveness analysis that attempts to assess the value of new innovations mainly from the perspective of consumer surplus, wrongly ignoring the incentives for innovation such criteria induce. ${ }^{6}$

The paper may be briefly outlined as follows. Section 2 estimates the share of social surplus appropriated by producers for the case of HIV/AIDS drugs. Section 3 discusses how much value is left in future HIV/AIDS research as estimated using our methods. Lastly, section 4 concludes.

\footnotetext{
${ }^{4}$ Our analysis includes future cohorts for several reasons. First, since the relevant R\&D has already been undertaken and the subsequent drugs already introduced, it is natural to focus on the lifetime returns to innovators (i.e. profits) and the comparable benefits to future infected cohorts. In fact, since the vast majority of sales of HIV/AIDS drugs from 1987 to 2000 occurred after 1995 , limiting our analysis to cohorts and firm profits affected to date would lower our estimated appropriation. For example, sales of HIV/AIDS drugs from 1987 to 2000 amounted to $\$ 11$ billion, while gross benefits to consumers were roughly $\$ 398$ billion, implying a surplus appropriation of well below 5\%.

${ }^{5}$ See e.g., Mansfield et al. (1977), Mansfield (1985), Levin et al. (1987), Hall (1996), and Nordhaus (2004).

${ }^{6}$ The literature is vast, but for examples, see Weinstein and Stason (1977), Johanneson and Weinstein (1993), Gold et al. (1996), Meltzer (1997), Drummond et al. (1997), Garber and Phelps (1997), Garber (2000), Cutler and McClellan (2001), and Cutler (2004).
} 


\section{Section 2: Surplus Appropriation for the New HIV/AIDS Drugs}

\subsection{Background on HIV/AIDS Drugs}

HIV is the causative agent of AIDS (Acquired Immunodeficiency Syndrome), a chronic disease characterized by suppression of an individual's immune system. The main mechanism of immune suppression is the destruction of the hosts' CD4 (Helper) T-cells - these cells stimulate the body's normal immune response to bacterial, fungal, and parasitic pathogens. AIDS can be diagnosed clinically or serologically (a low CD4 count). The clinical manifestation of AIDS includes the presence of opportunistic infections (infections that are otherwise harmless to an immune-competent individual), AIDS-related cancers, wasting, and dementia.

The time between initial HIV infection and the onset of AIDS varies, but is on average, several years even without treatment. Much can be done to slow this progression and the progression from AIDS to death. The four classes of drugs used to treat HIV/AIDS and the year of first marketing are shown in Table 1 .

Table 1: HIV/AIDS Anti-retroviral drug classes

\begin{tabular}{ccc}
\hline \hline Name & Abbreviation & Year of Introduction \\
\hline Nucleoside Reverse Transcriptase & NRTI & 1987 \\
Inhibitors & & 1995 \\
Protease Inhibitors & PI & 1996 \\
$\begin{array}{c}\text { Inhibitors } \\
\text { Non-Nucleoside Reverse Transcriptase }\end{array}$ & NNRTI & 2003 \\
Fusion Inhibitors & FI & 20 \\
\hline \hline
\end{tabular}

HIV utilizes RNA as its genetic code-upon entry into a cell, the HIV's own machinery (reverse transcriptase) transcribes this RNA into its DNA analog. This transcription process involves building the DNA from a series of small precursors called nucleotides. The NRTIs are essentially 'fake nucleotides'-they compete with the normal nucleotides and when incorporated into the budding DNA chain, prematurely terminate transcription. The NNRTIs do not mimic nucleotidesinstead, they directly bind to reverse transcriptase, rendering it inactive and thereby preventing the formation of DNA.

In the absence of any treatment, the DNA produced by the viruses' reverse transcriptase is able to integrate into the host DNA. That DNA is ultimately used by the host's machinery to produce a long, inactive poly-protein, a protein comprised of several smaller, active proteins. It is these smaller proteins that enable the newly replicated virus to infect and kill other Helper T-cells. The PIs act by preventing the conversion of the poly-protein into the smaller constituent 
proteins (this conversion is normally done by the HIV enzyme, protease, hence the name protease inhibitor). The final and most recently developed class of drugs, fusion inhibitors, act by a distinct mechanism-they prevent the initial attachment and entry of HIV into the Helper T-cell. Highly Active AntiRetroviral Therapy (HAART) combines drugs from several of the above classes-this combination is more effective in reducing HIV levels in the blood and slowing the development of viral resistance. These drugs are effective in lowering viral load and consequently increasing CD4 counts in both AIDS and HIV-only patients.

\subsection{Valuation Formulas}

In this section, we provide the theoretical underpinning for the economic value of newly introduced HIV/AIDS drugs. In short, for a given set of people that are diagnosed in a given year, we compare survival rates from HIV/AIDS before and after the introduction of Anti-Retroviral (ARV) drugs and attach a monetary value to that survival compared to a baseline survival when no drugs were available. We repeat this for the new set of cases, cohort by cohort, since the start of the epidemic and then aggregate up.

Since antiretrovirals are effective in slowing the transition from AIDS to death and from HIV to AIDS, any estimates of the value of added survival induced by these drugs should not only be restricted to AIDS patients. Instead, these estimates should also account for decreased rates of transition between HIV and AIDS. This suggests that any empirical specification should use survival curves conditional on a diagnosis of HIV as opposed to AIDS. The progression from initial HIV infection to death can be modeled in two steps (with two corresponding survival functions): the transition from HIV to AIDS and from AIDS to death. These two survival functions can be used to generate a new survival function, $S_{t}(d)$, summarizing the transition from HIV to death for individuals diagnosed with HIV in year t. This survival curve is assumed to be raised by the consumption of new drugs compared to the counterfactual survival curve $S_{o}(d)$ experienced by those infected in year zero, here taken to be 1979 .

Each year, there is a new cohort of HIV infected people (incidence). The initial cohort of HIV infected people face the survival curve $S_{o}(d)$. The gross consumer surplus, g, induced by the new drug consumption is calculated by multiplying the size of cohort $\mathrm{t}, \mathrm{n}_{\mathrm{t}}$, by the monetary value of increased survival and summing over all calendar years. Formally,

$$
g=\sum_{t=1980}^{2000} \beta^{t-1980} n_{\mathrm{t}} \cdot g_{t}
$$


where $g_{t}=g\left(S_{o}(d), S_{t}(d)\right)$, or the monetary value of increasing survival from the baseline survival $S_{o}(d)$ to the higher future survival faced by cohort $t, S_{t}(d)$.

The gain in survival, $\mathrm{g}_{\mathrm{t}}$, can be calculated using the infra-marginal valuation formula of Becker et al. (2005). They provide the value of survival gains for an infra-marginal change in survival from $S_{o}(d)$ to $S_{t}(d)$ under a yearly income y. Following Becker et al. (2005), this valuation is based on the willingness of an individual in cohort $t$ (with income $y_{t}$ ) to accept a decrease in survival from $S_{t}(d)$ to $S_{o}(d)$. Formally,

$$
\mathrm{V}\left[\mathrm{y}_{\mathrm{t}}+\mathrm{e}_{\mathrm{t}}, \mathrm{S}_{\mathrm{o}}(\mathrm{d})\right]=\mathrm{V}\left[\mathrm{y}_{\mathrm{t}}, \mathrm{S}_{\mathrm{t}}(\mathrm{d})\right]
$$

where $\mathrm{V}$ is the indirect lifetime utility function and $\mathrm{e}_{\mathrm{t}}$ is the yearly compensation required to make the hypothetical individual indifferent between the two survival frontiers. ${ }^{7}$ The lifetime value for the gain in survival is calculated by summing the yearly compensation $\left(e_{t}\right)$ over time, discounting by the rate of interest and the new survival probability. That is,

$$
g_{t}=\sum_{d=0}^{\infty} \beta^{d} \cdot S_{o}(d) \cdot e_{t}
$$

Becker et al. parameterize the instantaneous utility function to be:

$$
u(c)=\frac{c^{1-1 / \gamma}}{1-1 / \gamma}+\alpha
$$

This leads to the following expressions for the yearly "willingness to accept" infra-marginal changes in survival,

$$
e_{t}=\left[y_{t}^{1-1 / \gamma} \cdot \frac{A\left(S_{t}\right)}{A\left(S_{o}\right)}+\alpha \cdot(1-1 / \gamma) \cdot \frac{A\left(S_{t}\right)-A\left(S_{o}\right)}{A\left(S_{o}\right)}\right]^{\frac{\gamma}{\gamma-1}}-y_{t}
$$

where $A(S)$ is the present value of an annuity discounted by the rate of interest and the survival probability $\mathrm{S}$. That is,

$$
A\left(S_{t}\right)=\sum_{d=0}^{\infty} \beta^{d} \cdot S_{t}(d)
$$

The parameter $\alpha$ arises from a utility normalization and is estimated to be -14.97 . The intertemporal elasticity of substitution $(\gamma)$ is set to 1.25 , and the interest rate to $3 \%$. With the above parameter values and estimates of cohort-specific survival curves, we can use the above formulas to estimate the value of gains in survival under the willingness-to-accept criterion.

\footnotetext{
${ }^{7}$ Note that the use of yearly, as opposed to lifetime, income (y) and compensation (e) in expression 2 follows from the assumption that the discount rate on instantaneous utility equals the market rate of discount, i.e. the interest rate. For more details see Becker, et al. (2005).
} 
A major issue in using the above valuation formulas is how the income of the target population is determined. This is particularly relevant to consumers of HIV drugs, since they have lower than average incomes. This is, in part, due to an increasing proportion of newly infected individuals who are low-income and eligible for Medicaid. In addition, the disabling nature of the disease often causes individuals to leave work, losing both income and employer-sponsored insurance (Kates and Wilson, 2004). Simply using existing estimates of the value of life may greatly overstate the value of survival gains from AIDS research if those estimated values are based on the average income of the US population. In particular, if such estimates stem from wage-mortality tradeoffs among the employed population, they may overstate value of life estimates among the unemployed. Before developing the empirical counterparts of the above valuation expressions, we briefly discuss the epidemiology of HIV/AIDS.

\subsection{Time Series of HIV/AIDS}

Estimating the aggregate value of additional survival for all those diagnosed with HIV requires data on the incidence of HIV and cohort-specific survival conditional on the year of diagnosis of HIV (i.e. survival probabilities for cohorts diagnosed with HIV in 1984, 1985, etc). Only within the past ten years have a substantial number of states begun mandatory HIV reporting - prior to that, only AIDS cases were reported to the Centers for Disease Control and Prevention (CDC). This complicates the analysis for two reasons. First, estimates of HIV incidence are not as readily available as those of AIDS incidence. Second, there are no published cohort-specific survival curves with time zero being seroconversion (contraction of HIV). We address these issues, in turn, below.

Figure 1 graphs AIDS incidence, prevalence, and deaths from the CDC's HIV/AIDS Annual Sureveillance Reports. Since early estimates of HIV incidence are not available from reporting data (as is the case with AIDS), estimates of HIV incidence prior to 1990 were obtained from published figures using the method of "back-calculation" (Brookmeyer, 1991). Since 1990, the CDC has estimated incidence to be roughly 40,000 annually - this estimate is consistent with data on rates of transmission among hetero- and homo-sexuals and prevalence of both groups in the US. ${ }^{8}$ There have been over 900,000 diagnosed AIDS cases to date, with over 500,000 AIDS related deaths. There are slightly over 400,000 individuals currently living with AIDS and roughly 650,000 individuals living with HIV only.

\footnotetext{
${ }^{8}$ Communication with CDC.
} 
Figure 1: Estimates of HIV Incidence, AIDS Incidence, and Deaths from AIDS

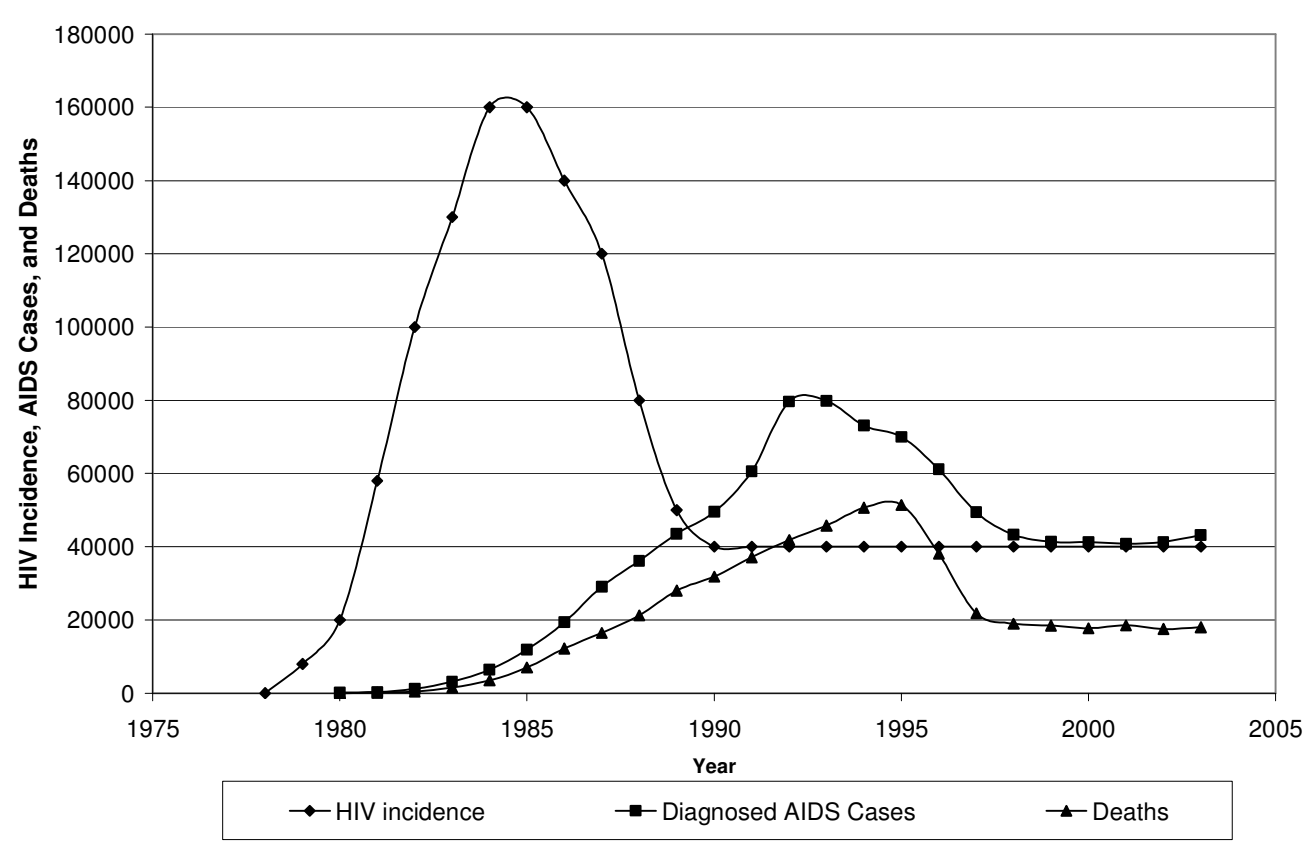

There are at least three points worth noting in Figure 1. First, large declines in AIDS deaths followed the introduction of Protease Inhibitors and Non-Nucleoside Reverse Transcriptase Inhibitors in 1995 and 1996. Second, there seem to be declines in AIDS diagnoses since 1995, which is consistent with an effect of ARVs on the transition from HIV to AIDS. Finally, the apparent increase in AIDS diagnoses around 1993 is, in part, due to a change in the definition of AIDS. Prior to 1993, a diagnosis of AIDS was based on the clinical finding of an opportunistic infection. After 1993, the diagnosis was expanded to include individuals with CD4 counts below 200 per cubic millimeter. This re-definition creates a problem in our construction of AIDS to death survival curves, which we address shortly.

\subsection{Estimating the Time from AIDS to Death}

As noted above, to our knowledge, there are no data available for cohort specific survival curves for the transition from HIV to death. To overcome this data limitation, we use data from several sources to construct estimates of these curves. Using 1) published cohort specific survival curves for AIDS patients (time zero being diagnosis of AIDS, as opposed to HIV) for each year from 1984-2000 and 2) survival curves for transition of HIV to AIDS for 1980-83 and 1996-1997, we 
construct survival curves for the transition of HIV to AIDS for 1984-2000. ${ }^{9}$ Under some assumptions, we use our estimated HIV to AIDS and AIDS to death survival curves to generate HIV to Death survival curves for each year of HIV diagnosis from 1979-2000. ${ }^{10}$ It is important to stress that our basic conclusions about the returns to HIV/AIDS R\&D will not depend on the methods used to generate these curves.

The earlier theoretical analysis requires the use of survival curves that span the entire range of lifetimes. The survival curves published by the CDC, however, are censored five years after diagnosis. There are two possible ways to overcome this limitation. One way is to fit the survival curves to known parametric forms (such as exponential, Weibull, or Gompertz). This is problematic for several reasons and is considered more carefully in the Appendix. The second way to project our survival curves forward, and the means we employ, is to assume that individuals who have survived five years since a diagnosis of AIDS experience future survival that is typical of, say, a normal 70 year-old male. Intuitively, individuals who have survived this long still face certain medical problems that lead to lower survival than other normal individuals their age. However, they may face survival probabilities that are similar to individuals substantially older than them. While the leading causes of death differ between the two groups, they do share some similarities-for example, the elderly can often die from pneumonia, which is also a common cause of death in AIDS patients. We describe the above estimation procedure more thoroughly and examine the robustness of our estimates in the Appendix.

Figure 2 presents estimated survival curves conditional on a diagnosis of AIDS for select years of diagnosis. AIDS is defined according to the post-93 definition to ensure comparability across years.

\footnotetext{
${ }^{9}$ Survival curves for AIDS patients: "Survival after AIDS Diagnosis in Adolescents and Adults during the Treatment Era," United States, 1984-1997, Lisa M. Lee, John M. Karon, Richard Selik, Joyce Neal, Patricia Fleming, JAMA, March 14, 2001--Vol. 285, No. 10. The AIDS survival curves are generated by following individuals in the official CDC HIV/AIDS Registry over time. This differs from the "period life-table" approach to generating survival curves.

${ }^{10}$ Prior to 1993, AIDS was defined by the presence of an opportunistic infection. After 1993, the definition was expanded to include individuals with low CD4 counts (serological diagnosis) as well. Since AIDS patients with opportunistic infections have poorer survival than those diagnosed serologically, a comparison of published survival curves for "AIDS" patients in 1984 and 2000 would overestimate the true increase in survival. We use data from 1993-1997, for which survival information exists under both pre- and post-1993 definitions, to compute an adjustment factor which is applied to AIDS survival data from 1984-1992. This results in estimates of survival from AIDS which are comparable over time. The details are presented in the Appendix.
} 
Figure 2: Survival from AIDS by Year of Diagnosis

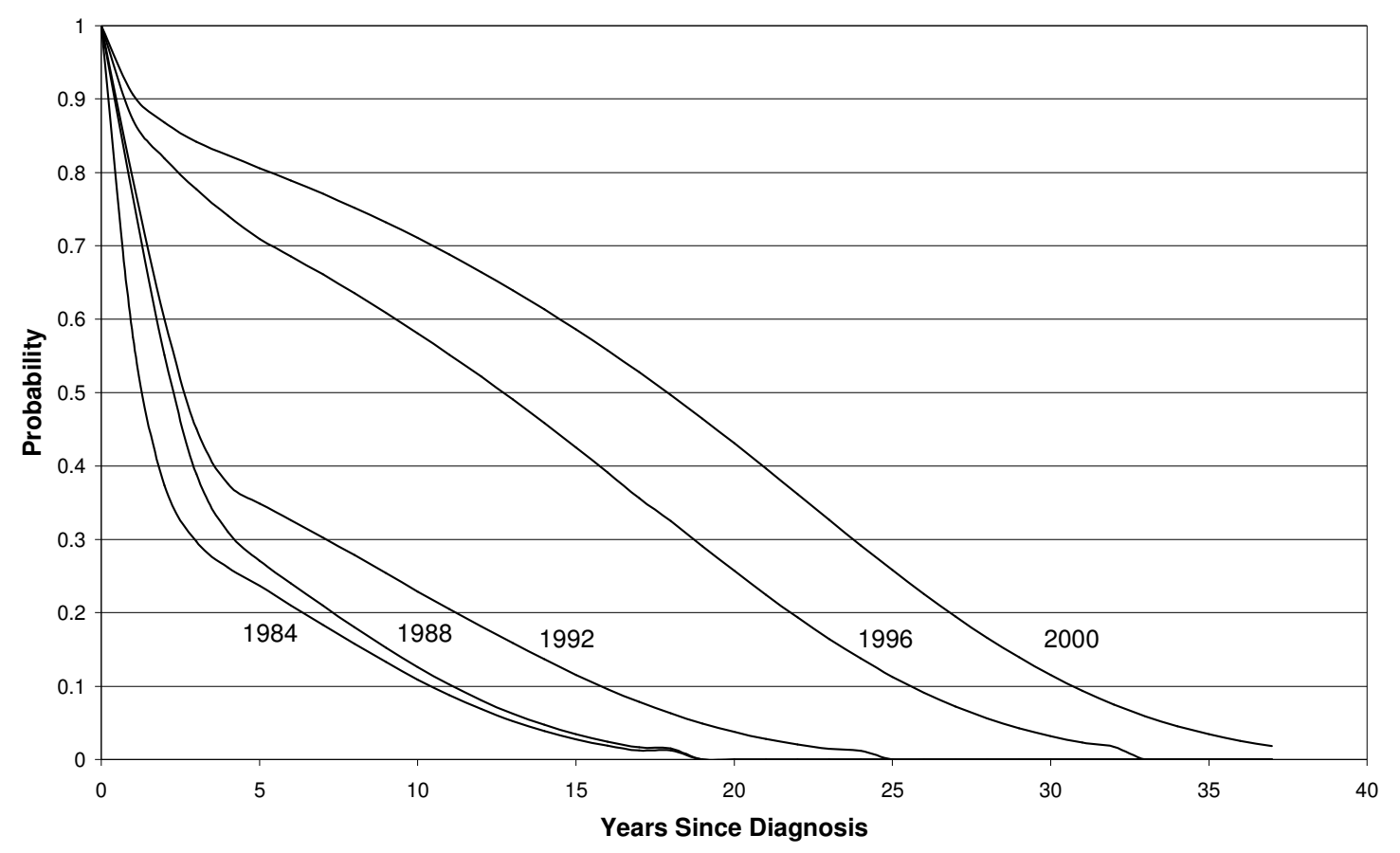

The above figure demonstrates the huge increases in survival experienced by later cohorts diagnosed with AIDS compared to their earlier counterparts. In fact, consistent with findings by Goldman et al. (2000) and Bhattacharya and Goldman (2003), the gains in survival arising from the early HIV/AIDS drugs (namely AZT) were marginal compared to the gains experienced due to the breakthrough drugs in the mid 1990's. The difference is particularly stark when comparing survival among individuals diagnosed with AIDS in 1996 to survival of those diagnosed in 1988 . The five year mortality rate is nearly fifty percentage points lower in 1996. Table 2 in the Appendix presents the life-expectancy from AIDS, by year of diagnosis. Our estimates suggest that life expectancy for AIDS patients has increased from 3 years in 1984 to 16.5 years in 2000.

\subsection{Estimating the Time from HIV Infection to Death}

As stated earlier, the final goal is to arrive at estimates of survival conditional on a diagnosis of HIV (not AIDS). The CDC implemented a program of confidential name-based reporting of HIV cases in 1994-this program was adopted by 25 states. The CDC has not published official estimates of survival from HIV to AIDS using this data. There are numerous studies in the medical literature, however, that follow individuals longitudinally to determine the time from HIV 
seroconversion to onset of AIDS. We use data from one such study (CASCADE Collaboration), which aggregates data from 38 smaller studies for which the date of seroconversion can be reliably estimated. Specifically, we use data on AIDSfree survival of HIV infected individuals in two periods, 1980-83 and 1996-97. ${ }^{11}$ For each of the two time periods, we have a single survival curve. The individuals in this study are drawn from Europe, Australia, and North America and consequently may not be fully representative of the HIV infected population in the US. However, comparisons with other estimates within the US show little difference.

With estimated AIDS-free survival curves for individuals infected with HIV in 1980-83 and 1996-1997 in hand, we estimate survival for each year between these two time periods using the following strategy. We assume that survival in each year from 1979 to 1983 is equivalent to the survival estimated for the four year period as a whole. Similarly, we assume that the AIDS-free survival for each year from 1997 to 2000 is equivalent to the estimated survival for 19961997. Using these two sets of survival curves as bounds for survival in the intermediate years, we assume that survival in the intermediate years evolves in a manner similar to the survival from AIDS to death during those same years, on which we have estimates. Specifically, we assume that the share of the total increase in HIV to AIDS survival from 1980-2000 that occurs between 1984 and 1985 is equal to the share of total improvement in AIDS survival that takes place between those same years. This implicitly assumes that between years, treatment affects the transition from HIV to AIDS and AIDS to death relatively the same, the frame of reference being the total improvement in survival for each group from 1980-2000.

Using the previously estimated survival curves for AIDS and the AIDSfree survival for HIV infected individuals, we generate survival curves conditional on an infection with HIV for each year from 1979 to 2000. The details behind this estimation are presented in the Appendix. Figure 3 presents the survival after an infection with HIV, by year of infection. Table 3 in the Appendix presents the average time to onset of AIDS and the life-expectancy after HIV infection for various years of HIV infection.

\footnotetext{
11 The AIDS-free survival in the CASCADE study is censored at 13 years. We fit the remainder of each survival curve using the Weibull specification. The fact the published survival curves extend 13 years allows us to reliably do so.
} 
Figure 3: Survival from HIV by Year of Infection

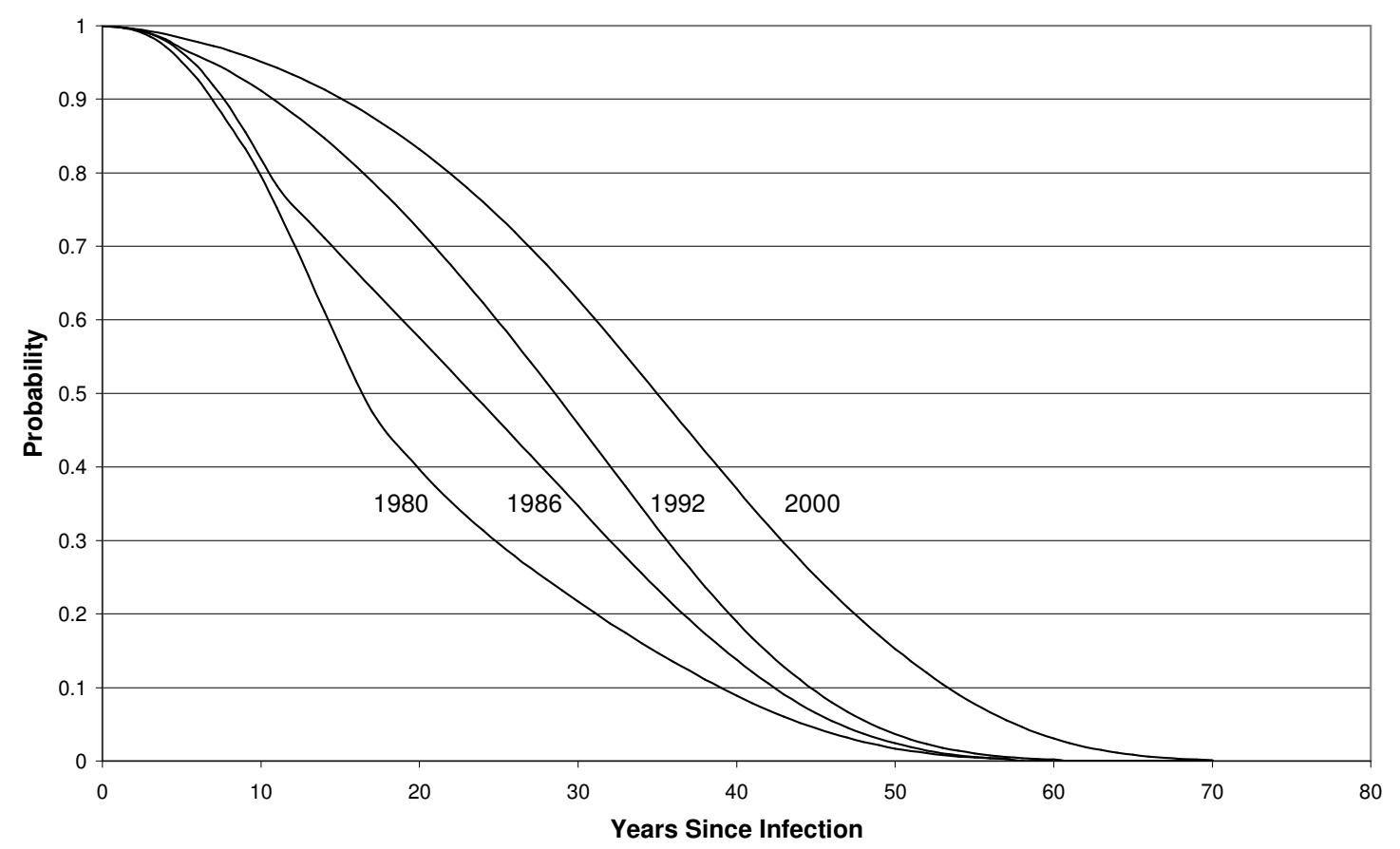

From the above graph and Table 3 in the Appendix, it is clear that advances in treatment have led to increases in both the time to onset of AIDS and the period of time alive after a diagnosis of AIDS. The life-expectancy of the average individual infected with HIV has increased roughly 15 years since the start of the epidemic, from 19 to 34 years. These figures are slightly larger than those in the literature-for example, the mean incubation time of HIV (time from HIV to AIDS) in the early 1980's is generally thought to be between 10 and 11 years, while the life-expectancy after AIDS is 3 - 4 years. These estimates suggest an initial life-expectancy from HIV of almost 15 years, so our above estimates are not far off.

To further verify the reasonableness of our estimates, we can use our estimated annual HIV survival curves and reported data on annual HIV incidence to estimate the current number of individuals infected with HIV/AIDS. We can then compare this imputed figure to published figures from the CDC. Specifically, we multiply the incidence of HIV in a given year by the proportion of individuals infected with HIV in that year who survive until 2003, as determined from the estimated survivals. Doing so from the very beginning of the epidemic, we estimate $1,055,097$ to be living with HIV/AIDS in 2003. This can be compared to the CDC estimate of 1,067,522, a difference of only 12,424 people! It is important to note that these differences will not impact the sheer 
magnitude of the value of gains in survival. ${ }^{12}$ With estimated survival for various cohorts infected with HIV in hand, we now turn to valuing the gains in survival.

\subsection{Valuing the Gains in Survival due to HIV/AIDS Drugs}

Using survival of an individual infected with HIV in 1979 as a benchmark, we use the valuation formulas described earlier to compute the lifetime value to an individual of increasing survival to that of someone infected with HIV in a given later year. Aggregate values for each year are computed by multiplying that year's incidence of HIV by the value of increased survival experienced by a single individual in that cohort. Note that these figures ignore the behavioral change that raises incidence in response to better treatments, which we discuss more fully in the Conclusion. The income used in the calculations is GDP per capita (in year 2000 dollars). All figures are discounted back to 1980.

12 The calculated survival functions suggest an upper bound of the increase in life-expectancy attributable to HIV/AIDS drugs. This is due to concomitant advances in the treatment of HIV/AIDS in areas other than anti-retrovirals. From 1984 to 2000, life expectancy increased by nearly fifteen years for individuals infected with HIV and thirteen years for individuals diagnosed with AIDS. This can be compared to the estimates of Lichtenberg (2005), who estimates increases in AIDS life-expectancy of nearly 22 years from 1993 to 2001, 13 years of which is attributable to HIV/AIDS drugs. 
Table 2: Value of Gains in Survival for HIV Infected Individuals

\begin{tabular}{cccc}
\hline \hline & & \multicolumn{2}{c}{ Value of Survival Gains $(\$)$} \\
\hline $\begin{array}{c}\text { Year of } \\
\text { HIV } \\
\text { Infection }\end{array}$ & $\begin{array}{c}\text { HIV } \\
\text { Incidence }\end{array}$ & $\begin{array}{c}\text { Individual } \\
(\$)\end{array}$ & $\begin{array}{c}\text { Aggregate } \\
\text { (\$ Billion) }\end{array}$ \\
\hline 1980 & 20,000 & 17,655 & 0.35 \\
1981 & 58,000 & 39,361 & 2.28 \\
1982 & 100,000 & 60,256 & 6.03 \\
1983 & 130,000 & 84,941 & 11.04 \\
1984 & 160,000 & 116,156 & 18.59 \\
1985 & 160,000 & 146,874 & 23.50 \\
1986 & 140,000 & 178,968 & 25.06 \\
1987 & 120,000 & 214,389 & 25.73 \\
1988 & 80,000 & 250,284 & 20.02 \\
1989 & 50,000 & 287,924 & 14.40 \\
1990 & 40,000 & 322,311 & 12.89 \\
1991 & 40,000 & 339,957 & 13.60 \\
1992 & 40,000 & 383,328 & 15.33 \\
1993 & 40,000 & 432,908 & 17.32 \\
1994 & 40,000 & 567,422 & 22.70 \\
1995 & 40,000 & 613,839 & 24.55 \\
1996 & 40,000 & 696,951 & 27.88 \\
1997 & 40,000 & 718,603 & 28.74 \\
1998 & 40,000 & 730,179 & 29.21 \\
1999 & 40,000 & 738,839 & 29.55 \\
2000 & 40,000 & 740,515 & 29.62 \\
\hline \multicolumn{3}{c}{ Total Discounted Value } & 398 \\
\hline \hline
\end{tabular}

All figures are discounted to 1980 and are in year 2000 dollars.

The above results suggest that the aggregate value of improved survival experienced by all individuals infected with HIV to date has been nearly $\$ 400$ billion. This, of course, ignores the value of increasing survival for all individuals who have not contracted HIV yet, but will do so in the future. We add this component to our calculations later in the section.

We can compare our value of life estimates with other estimates in the literature. One way of doing this is by calculating the gain in life-expectancy induced by our estimated survival functions and then using existing estimates of the value of a life-year to value the changes in life-expectancy induced by HIV drug consumption. Since life-expectancy associated with a survival curve is its 
sum over ages, if we have an estimate of the value of a life-year, $v$, the value of increasing survival from a benchmark of $S_{o}(d)$ to that of cohort t, $S_{t}(d)$ satisfies

$$
v \cdot\left[\sum_{d>0}^{\infty} S_{t}(d)-\sum_{d>0}^{\infty} S_{o}(d)\right]
$$

This implicitly assumes an age-invariant value of a life-year, but adjusting this value for age may, of course, also be done. Using common estimates of the value of a life-year in the range of $\$ 100$ thousand (Cutler and Richardson, 1998), we can calculate the value of increasing life expectancy from the benchmark to that of a cohort diagnosed in a given year. Table 3 presents the value of the gain in life expectancy based on the value of a life-year equal to $\$ 100,000$. Note that when calculating the value of increased life expectancy using the value of a lifeyear, each additional year of life expectancy is discounted back to 1980 . 
Table 3: Comparing the value of life to estimates in the literature

\begin{tabular}{|c|c|c|c|}
\hline $\begin{array}{l}\text { Year of HIV } \\
\text { Infection }\end{array}$ & $\begin{array}{l}\text { Estimated } \\
\text { Value of } \\
\text { Life } \\
\text { (\$) }\end{array}$ & $\begin{array}{c}\text { Increase in } \\
\text { Life } \\
\text { Expectancy } \\
\text { Relative to } \\
1979 \\
\text { (Years) }\end{array}$ & $\begin{array}{l}\text { Value of Gain } \\
\text { in Life } \\
\text { Expectancy } \\
\text { Using Value of } \\
\text { a Life-Year } \\
(\$)\end{array}$ \\
\hline 1980 & 17,655 & 0.6 & 60,000 \\
\hline 1981 & 39,361 & 1.2 & 116,505 \\
\hline 1982 & 60,256 & 1.9 & 179,093 \\
\hline 1983 & 84,941 & 2.6 & 237,937 \\
\hline 1984 & 116,156 & 3.2 & 284,316 \\
\hline 1985 & 146,874 & 3.9 & 336,418 \\
\hline 1986 & 178,968 & 4.6 & 385,243 \\
\hline 1987 & 214,389 & 5.3 & 430,939 \\
\hline 1988 & 250,284 & 5.9 & 465,752 \\
\hline 1989 & 287,924 & 6.6 & 505,835 \\
\hline 1990 & 322,311 & 7.3 & 543,189 \\
\hline 1991 & 339,957 & 7.8 & 563,489 \\
\hline 1992 & 383,328 & 8.7 & 610,201 \\
\hline 1993 & 432,908 & 9.7 & 660,523 \\
\hline 1994 & 567,422 & 12.4 & 819,786 \\
\hline 1995 & 613,839 & 13.3 & 853,677 \\
\hline 1996 & 696,951 & 14.8 & 922,287 \\
\hline 1997 & 718,603 & 15.0 & 907,525 \\
\hline 1998 & 730,179 & 15.1 & 886,966 \\
\hline 1999 & 738,839 & 15.1 & 861,132 \\
\hline 2000 & 740,515 & 15.1 & 836,051 \\
\hline
\end{tabular}

All figures are discounted to 1980 and are in year 2000 dollars.

For recent years, the value of increased life expectancy derived from the value of a life-year is similar to our value of life estimates, amounting to nearly $\$ 750$ thousand for year 2000 survival.

As alluded to earlier, the consumer benefit from HIV/AIDS drugs does not simply include the aggregate value calculated to date, but also includes the value to future cohorts of increased survival. We can forecast the value to future cohorts of HIV infected individuals by assuming that all cohorts experience the same aggregate gain in survival $g_{t}$ as the last cohort, 2000. Hence, we assume

$$
g_{2000+t}=g_{2000} \forall t>0
$$


Assuming that the future incidence of HIV is equivalent to the last period, we can calculate the discounted sum of future gains for individuals infected with HIV in the future. We then add this amount to the value to date calculated earlier, namely $\$ 398$ billion. This leads to an aggregate value of increased survival for all past and future cohorts of nearly $\$ 1.4$ trillion. In the next section, we calculate the lifetime profits and variable costs associated with production. This allows us to decompose the total value of HIV/AIDS drugs into consumer surplus, producer surplus (profits), and costs.

\subsection{Dividing the Social Surplus into Producer and Consumer Surplus}

The overall producer surplus obtained from $R \& D$ is determined by the present value of producer surplus to firms producing HIV/AIDS drugs. Specifically, it is:

$$
\pi=\sum_{t=1980}^{\infty} \beta^{t-1980} \cdot \pi_{t}
$$

An upper bound of producer surplus is the aggregate sales for HIV/AIDS drugs. An alternative lower estimate takes out variable costs. We do this by applying existing estimates of markups for brand-name drugs estimated from patent expirations, and applying those markups to the observed aggregate sales.

Figure 4 presents estimates of national spending on HIV/AIDS drugs broken down by public and private payers. The estimates for total spending are from IMS Health and are reported in Lichtenberg (2005). Public spending is approximated by the sum of Medicaid and ADAP expenditures. The Medicaid estimates include both federal and state contributions and were calculated from the Medicaid State Drug Utilization Data using National Drug Codes (NDC) for all antiretrovirals introduced since $1987 .^{13}$ Medicaid expenditure on HIV/AIDS drugs is unavailable prior to the last quarter of 1991-this is likely because Medicaid began its Prescription Drug Rebate Program (for all drugs, not just ARVs) only in 1990. ${ }^{14}$ Data on ADAP expenditures are unavailable prior to 1996, though it was informally covering some individuals through the Ryan White CARE Program prior to that. ${ }^{15}$

\footnotetext{
${ }^{13} \mathrm{http} / / /$ www.cms.hhs.gov/medicaid/drugs/drug5.asp

${ }^{14}$ See "Key Milestones in CMS Programs" for more detailed information: http://www.cms.hhs.gov/about/history/milestones.asp

15 Through communication with Kaiser Family Foundation.
} 
Figure 4: National Spending on HIV/AIDS Drugs

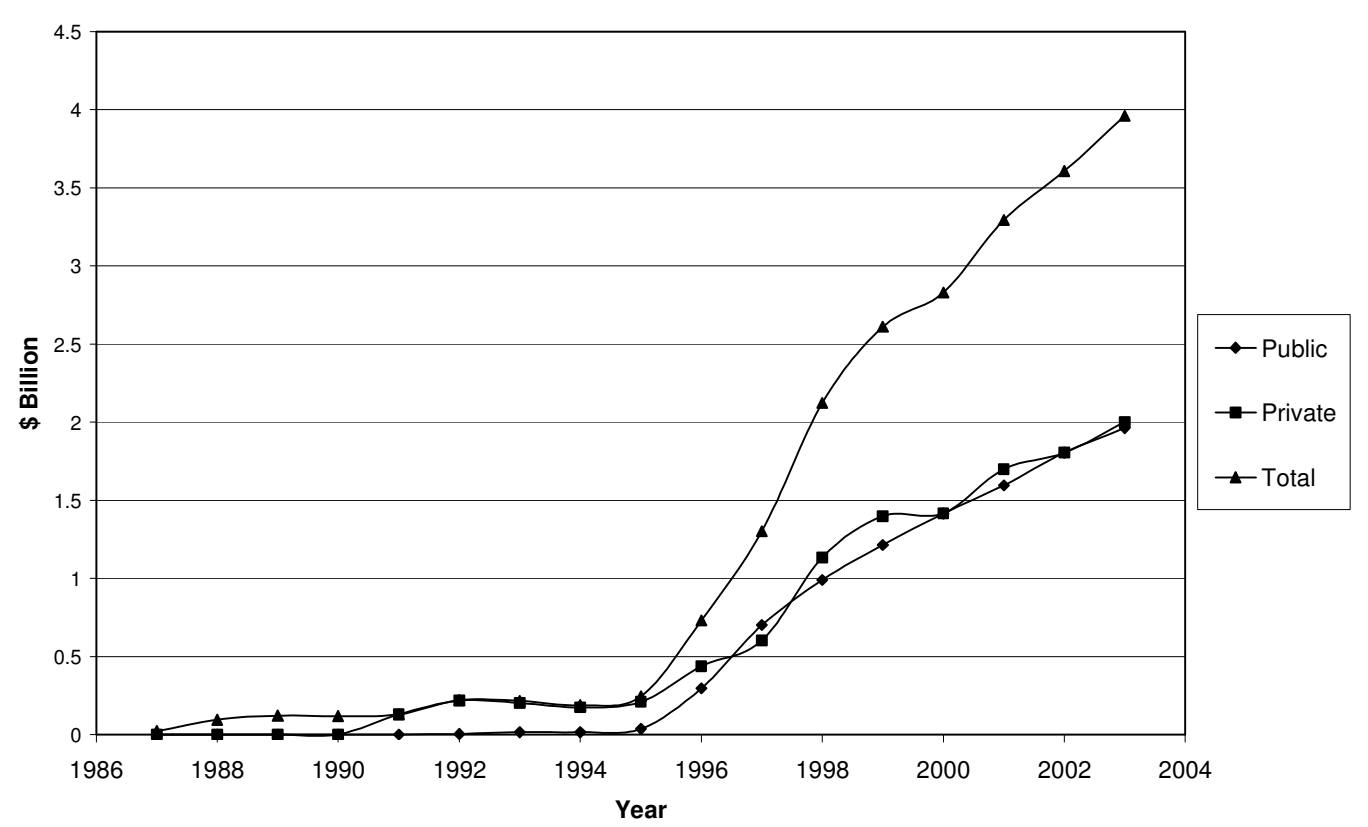

Figure 4 demonstrates the large increase in spending on HIV/AIDS drugs in the past ten years. Since 1995, spending has increased from $\$ 250$ million to almost $\$ 4$ billion, largely due to increased spending on protease inhibitors and nucleoside reverse transcriptase inhibitors. Figure 5 also depicts the large share of total spending on HIV/AIDS drugs that comes from public sources, nearly $50 \%$ from 1997 onwards.

In order to estimate the aggregate lifetime profits from HIV/AIDS drugs, we must make assumptions about future sales. One possibility is to assume that future sales are equal to last-period sales, in this case national sales of HIV/AIDS drugs in 2000. We use estimates from the literature on the prices of generic drugs relative to their branded counterparts to assume variable costs to be no more than $15 \%$ of sales (Caves, et al., 1991). ${ }^{16}$ With sales in the future being equivalent to year 2000's patent-protected sales, we estimate lifetime sales to be roughly $\$ 74$ billion. This suggests a lifetime variable cost of production of $\$ 11.1$ billion (74 $\mathrm{x}$ 0.15 ) and lifetime profits of $\$ 62.9$ billion.

Using the above figures, we can decompose the total lifetime value of HIV/AIDS drugs into consumer surplus, producer surplus (profits), and

${ }^{16}$ In "Patent Expiration, Entry, and Competition in the U.S. Pharmaceutical Industry," R. Caves, M. Whinston, and M. Hurwitz estimate that with 20 generic competitors, the ratio of prices between generic and brand drugs is roughly $17 \%$. We use the price of generic drugs as an upper bound of the marginal costs of production. 
production costs. Recall that we estimated the total value to be nearly $\$ 1.4$ trillion, discounted to 1980 in year 2000 dollars. This amounts to a lifetime consumer surplus of roughly $\$ 1.33$ trillion ( $\$ 1.4$ trillion $-\$ 74$ billion). With a social surplus (total value net of production costs) of $\$ 1.38$ trillion, almost $95 \%$ is captured in the form of consumer surplus.

\section{Section 3: Potential Gains from Future R\&D}

The previous analysis of the value of life gains induced by HIV/AIDS drugs introduced to date suggested a gross benefit to consumers of nearly $\$ 1.4$ trillion. This begs the question: In the current environment in which several HIV/AIDS drugs already exist, what is the added value of a complete cure for AIDS? Figure 5 below illustrates this question.

Figure 5: Survival from HIV Compared to Normal Survival

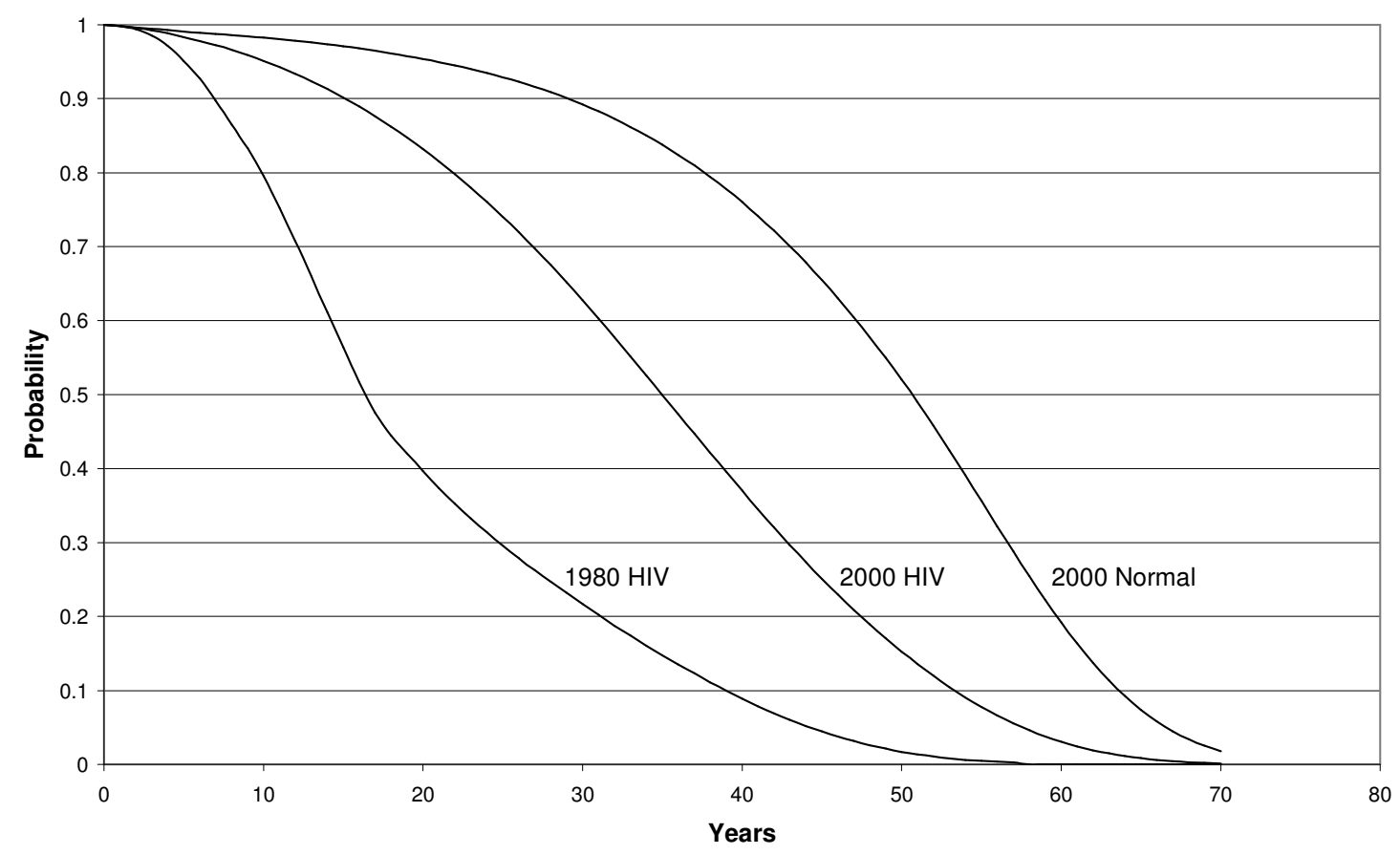

As demonstrated earlier, the survival for an individual infected with HIV has improved dramatically since 1980. Also plotted in Figure 5 is the survival of a normal, healthy 30 year-old individual in 2000 - the area between the survival of an individual infected with HIV in 2000 and that of a healthy individual in the same year represents the gain in life-expectancy for the HIV-infected individual from a cure for AIDS. The added value from a cure for AIDS is divided among 
two groups, those individuals who have contracted HIV in the past and can now resume normal, healthy lives and those individuals who contract HIV in the future and would otherwise experience survival typical of someone infected with HIV in 2000.

We can use the previously described methodology to estimate the added value from a cure for AIDS. Supposing a complete cure becomes available in 2010, we can modify our survival curves to account for a complete cure that restores survival to that of normal individuals. ${ }^{17}$ For example, these modifications take into account that an individual who survives to 2010 after contracting HIV at the age of 30 in 1990 follows survival of a healthy 50 year-old after being cured of HIV/AIDS. Essentially replicating our earlier analysis, we estimate the value to increased survival induced by both drugs introduced to date and a cure introduced in 2010 to be nearly $\$ 3.2$ trillion. Recall that the value of life induced by drugs introduced to date (with no cure) was estimated to be roughly $\$ 1.4$ trillion. This suggests that there is almost $\$ 1.8$ trillion of gross benefit to be had from a complete cure for AIDS. This raises the question of whether producers should be appropriated more surplus to close the remaining gap in HIV/AIDS survival.

\section{Section 4: Conclusion}

The value of an innovation may be divided into the gains to consumers and innovators. We estimated that for the HIV/AIDS therapies that entered the market from the late 1980's onwards, innovators appropriated only 5\% of the social surplus arising from these new technologies.

Despite the high prices of these drugs to patients and health plans, the low share of social surplus going to innovators raises concerns about advocating costeffectiveness criteria that would further reduce this share, and hence further reduce incentives for innovation. In particular, popular technology assessment criteria in healthcare going under the rubric of "cost-effectiveness" often implicitly maximize consumer surplus, which is consistent with maximizing static efficiency after an innovation has been developed. Dynamic efficiency, however, aligns the social costs and benefits of R\&D and is therefore determined by how much of the social surplus from a new technology is appropriated by producers.

Our findings suggest several questions to be addressed by future research. First, why is the share of surplus appropriated by producers so small and the costeffectiveness so seemingly high? One may be tempted to argue that there is a lack of market power of those holding patents on these new technologies due to therapeutic competition within drug classes. However, this certainly does not

\footnotetext{
${ }^{17}$ Recall that these survival curves already account for improved survival due to drugs introduced to date.
} 
seem to be the case for the breakthrough drugs in HIV/AIDS. Furthermore, in a related theoretical analysis, Philipson and Jena (2005) show that even if substitutes do not exist and patents are very broad, as when demand is highly inelastic, the share of the social surplus allocated to the producer may be very small.

Second, the small estimated share of social surplus appropriated by investors sheds important light on the recent growth of alternative funding mechanisms to stimulate HIV/AIDS research, e.g. through advance purchasing contracts of governments or private foundations. ${ }^{18}$ Given that there is a social surplus above a trillion that is not appropriated by R\&D investors, a few billion dollars added to stimulate innovation, as these public or private contracts seem to provide, seems to pale in comparison to the missed consumer surplus not appropriated.

Third, the economic epidemiology of chronic infectious diseases may alter the social value of HIV/AIDS drugs (Philipson, 2000). For example, one behavioral response to treatment may be an increase in incidence due to a lower cost of risky behavior. This might be mitigated by the longer life-expectancies (and prolonged ability to infect others) of HIV infected individuals receiving treatment. Offsetting this second effect, however, is the fact that current treatments lower the viral load and reduce the probability of infection at any point in time. While these external effects may alter the social value of HIV/AIDS drugs, their effect on the private value, which we consider here and is the target of producer appropriation efforts, is likely limited.

Finally, the peculiar aspects of healthcare markets may raise some nonstandard issues regarding the efficient form of surplus appropriation. One issue concerns the effect of altruism, which seemingly motivates much of public financing, on optimal technology adoption. ${ }^{19}$ A second concerns the effect of expost inefficiencies such as moral hazard. A third concerns the impact of the joint demand of physicians and patients as would be the case of the pharmaceutical industry considered here.

Our analysis and evidence, if they generalize to other technologies, suggest that interventions should be sought to attempt to raise producer surplus levels for new technologies. Even though this would lead to lower observed levels of cost-effectiveness for these technologies, dynamic efficiency would be raised.

\footnotetext{
${ }^{18}$ See e.g. The Center for Global Development (2005) and the efforts undertaken by The Gates Foundation (2005).

${ }^{19}$ Philipson and Mechoulan (2003) discuss optimal technology assessment in the presence of altruism that motivates public healthcare delivery, in general, and R\&D into third-world diseases, in particular.
} 


\section{Appendix}

\section{Adjustment of AIDS Survival Data from 1984-1992 for Changes in AIDS Definition}

Let $N_{O I}^{t}$ and $N_{S}^{t}$ be the shares of newly diagnosed AIDS cases in year $t$ based on opportunistic infection (OI) and CD4 count (S), respectively. They sum to one. Let $S_{O I}^{t}(d)$ and $S_{S}^{t}(d)$ be the corresponding survival curves. Under the pre-1993 definition, a diagnosis of AIDS includes only those individuals with an OI. Under this definition, the proportion alive after $\mathrm{d}$ periods is:

$$
A_{P R E}^{t}(d)=S_{O I}^{t}(d)
$$

Under the post-1993 definition, a diagnosis of AIDS includes those with an OI and those with a low CD4 count. The proportion alive after $\mathrm{d}$ periods under the post-1993 definition is,

$$
A_{P O S T}^{t}(d)=N_{O I}^{t}(d) \cdot S_{O I}^{t}(d)+N_{S}^{t}(d) \cdot S_{S}^{t}(d)
$$

a weighted average of the two survival functions. Note that $A_{P O S T}^{t}(d)$ is the survival curve conditional on a diagnosis of AIDS used by the CDC after 1993. For 1993-1997, we have survival curves conditional on a diagnosis of AIDS for both pre and post-1993 AIDS case definitions - that is, we have $A_{P R E}^{t}(d)$ and $A_{\text {POST }}^{t}(d)$ for $t=1993-1997$. Subtracting the two curves, we obtain,

$$
\begin{aligned}
A_{P O S T}^{t}(d)-A_{P R E}^{t} & =N_{O I}^{t}(d) \cdot S_{O I}^{t}(d)+N_{S}^{t}(d) \cdot S_{S}^{t}(d)-S_{O I}^{t}(d) \\
& =S_{O I}^{t}(d) \cdot\left(N_{O I}^{t}(d)-1\right)+N_{S}^{t}(d) \cdot S_{S}^{t}(d) \\
& =S_{O I}^{t}(d) \cdot\left(-N_{S}^{t}(d)\right)+N_{S}^{t}(d) \cdot S_{S}^{t}(d) \\
& =N_{S}^{t}(d) \cdot\left(S_{S}^{t}(d)-S_{O I}^{t}(d)\right) .
\end{aligned}
$$

We can rewrite this as

$$
A_{P O S T}^{t}(d)=N_{S}^{t}(d) \cdot\left(S_{S}^{t}(d)-S_{O I}^{t}(d)\right)+A_{P R E}^{t}(d) .
$$

This expression suggests two ways of estimating $A_{P O S T}^{t}(d)$ for years prior to 1993 using survival curves available for those years, namely $A_{P R E}^{t}(d)$.

\section{Case 1:}

First, we might simply average $N_{S}^{t}(d) \cdot\left(S_{S}^{t}(d)-S_{O I}^{t}(d)\right)$ for $t=1993-1997$, and add this correction factor to $A_{P R E}^{t}(d)$ for years before 1993. Instead of averaging, we might alternatively apply $N_{S}^{1993}(d) \cdot\left(S_{S}^{1993}(d)-S_{O I}^{1993}(d)\right)$ to all previous years. 


\section{Case 2:}

Second, since $A_{P O S T}^{t}(d), A_{P R E}^{t}(d)=S_{O I}^{t}(d)$, and $N_{S}^{t}(d)$ are known for 1993-1997, we can use these to back-calculate $S_{S}^{t}(d)$ for those same years. Since $N_{S}^{t}(d)$ and $S_{S}^{t}(d)$ are not known for years prior to 1993, we might use 1993 values for all calculations. That is,

$$
\operatorname{Est}\left[A_{P O S T}^{t}(d)\right]=N_{S}^{1993}(d) \cdot\left(S_{S}^{1993}(d)-S_{O I}^{t}(d)\right)+A_{P R E}^{t}(d) \text { for } t<1993 \text {. }
$$

Given that the true correction factor for $A_{P R E}^{t}(d)$ is $N_{S}^{t}(d) \cdot\left(S_{S}^{t}(d)-S_{O I}^{t}(d)\right)$, we can compare this to the two cases above. For notational convenience, let $t=1993$ and for Case 1, consider $N_{S}^{1993}(d) \cdot\left(S_{S}^{1993}(d)-S_{O I}^{1993}(d)\right)$ as opposed to the average. Consider Case 2 first. The true correction factor $N_{S}^{1984}(d) \cdot\left(S_{S}^{1984}(d)-S_{O I}^{1984}(d)\right)$ will be less than the correction factor in Case 2, $N_{S}^{1993}(d) \cdot\left(S_{S}^{1993}(d)-S_{O I}^{1984}(d)\right) \quad, \quad$ since $\quad S_{S}^{1993}(d)>S_{S}^{1984}(d) \quad$ and $N_{S}^{1993}(d)>N_{S}^{1984}(d)$. The latter is true since a greater share of newly diagnosed AIDS cases are likely to be only serologically diagnosed in the later years due to better drug therapy. Thus, the correction factor for Case 2 would be an upper bound of the true correction factor-estimated survival curves would overstate the true survival curves. Reversely, $N_{S}^{1984}(d) \cdot\left(S_{S}^{1984}(d)-S_{O I}^{1984}(d)\right)$ is likely to be closer to $N_{S}^{1993}(d) \cdot\left(S_{S}^{1993}(d)-S_{O I}^{1993}(d)\right)$, the correction factor for Case 1 . This is because the effects of $N_{S}^{1993}(d)$ and $S_{S}^{1993}(d)$ are in part mitigated by the fact that $S_{O I}^{1993}(d)>S_{O I}^{1984}(d)$, which brings correction factor 1 closer towards the true correction factor. Consequently, the first correction factor is used to adjust the pre-1993 data. ${ }^{20}$

${ }^{20}$ One might alternatively consider a multiplicative adjustment factor in which $A_{P O S T}^{t}(d)$ is estimated for years prior to 1993 by simply multiplying $A_{P R E}^{t}(d)$ by $\frac{A_{P O S T}^{1993}(d)}{A_{P R E}^{1993}(d)}$. We do not do this for two reasons. First, the theoretical relationship between $A_{P O S T}^{t}(d)$ and $A_{P R E}^{t}(d)$ is additive. Second, a multiplicative adjustment factor would result in values of [ $A_{P R E}^{t}(d)$ $\left.A_{P R E}^{t}(d)\right]$ that are low for early years (since the base by which the adjustment factor is multiplied is smaller). This is inconsistent with the data, which demonstrates that, for the years available, this difference is roughly independent of the level of survival. 


\section{Estimating Survival from AIDS}

Parametric estimation of AIDS survival curves published by the CDC is problematic for several reasons. First, the exponential distribution has a constant hazard, which is rejected in our data-in our case, the non-parametric plots exhibit a declining hazard. Second, the Gompertz specification, which is commonly used to characterize normal life tables, is inconsistent with the survival patterns seen in AIDS patients. Third, since survival curves after the mid-90's exhibit almost 50\% survival in the first five years, out-of-sample predictions of future survival are unreliable. For example, fitting the 1995 survival curve to the Gompertz specification results in nearly $50 \%$ of individuals still alive 10,000 months after diagnosis of AIDS — similar results hold for the Weibull. Note that is not a problem with earlier years. For example, fitting the 1984 survival curve to the Weibull distribution results in nearly all individuals dead within 20 years of diagnosis. This is due to the fact that, unlike survival in later years, only $20 \%$ of individuals survive past five years of diagnosis.

Another way to project our survival curves forward is to assume that conditional on surviving five years after a diagnosis of AIDS, future survival follows the survival of a normal individual conditional on reaching age $\mathrm{Y}$, where $\mathrm{Y}$ is determined by the following expression,

$\mathrm{S}_{\mathrm{AIDS}}(\mathrm{d}$ ISurviving 5 years since diagnosis in year $\mathrm{t})=\mathrm{S}(\mathrm{d} \mid \mathrm{Y}$ years old in year $\mathrm{t}+5)$

The value of Y should differ across diagnosis cohorts. That is, an individual who is alive in 1990 after being diagnosed with AIDS five years earlier will certainly face different survival prospects than an analogous individual ten years later. Our intuition for generating values of $\mathrm{Y}$ is the following. Individuals diagnosed with AIDS in 1984 experienced a death rate of nearly $75 \%$ within the first five years. We can use survival curves for normal individuals in 1984 to determine which age group $\mathrm{X}$ experienced a similar death rate over the course of five years. We can then use the survival curve of $\mathrm{Y}$ year-olds in 1989 (where $\mathrm{Y}=\mathrm{X}+5$ ) to project the 1984 AIDS survival curve past five years of diagnosis. Again, the idea behind this method is that normal elderly individuals who face similar prospects for five-year survival as do younger AIDS patients may also face similar survival rates later on.

In the actual estimation, we restrict our attention to changes in survival within the last year of the five-year period. Specifically, instead of considering the rate of death over the five-year period after diagnosis, we consider the rate of death between years four and five. We then determine the ages of normal 
individuals with similar one-year death rates. ${ }^{21}$ The estimated 'AIDS survival equivalent ages' are presented in Appendix Table 1. Figure 1 in this Appendix compares projected survival curves generated by the parameterization and imputation methods. For the years in which both methods were used, 1984-1993, the estimated survival curves are quite similar.

Table 1: Age of Normal Cohort Whose 1-Year Death Rate is Equivalent to AIDS Death Rate between Years 4 and 5 Post-Diagnosis

\begin{tabular}{cc}
\hline \hline $\begin{array}{c}\text { Year of AIDS } \\
\text { Diagnosis }\end{array}$ & Age \\
\hline 1984 & 86 \\
1985 & 86 \\
1986 & 86 \\
1987 & 86 \\
1988 & 87 \\
1989 & 87 \\
1990 & 85 \\
1991 & 84 \\
1992 & 81 \\
1993 & 78 \\
1994 & 73 \\
1995 & 73 \\
1996 & 73 \\
1997 & 73 \\
1998 & 72 \\
1999 & 68 \\
2000 & 68 \\
\hline \hline
\end{tabular}

${ }^{21}$ Since individuals comprising the latter part of the AIDS survival curve might differ systematically from those on the early part, we focus on the latter part when generating our projections. 
Figure 1: Comparison of AIDS Survival Generated by Parameterization versus Imputation

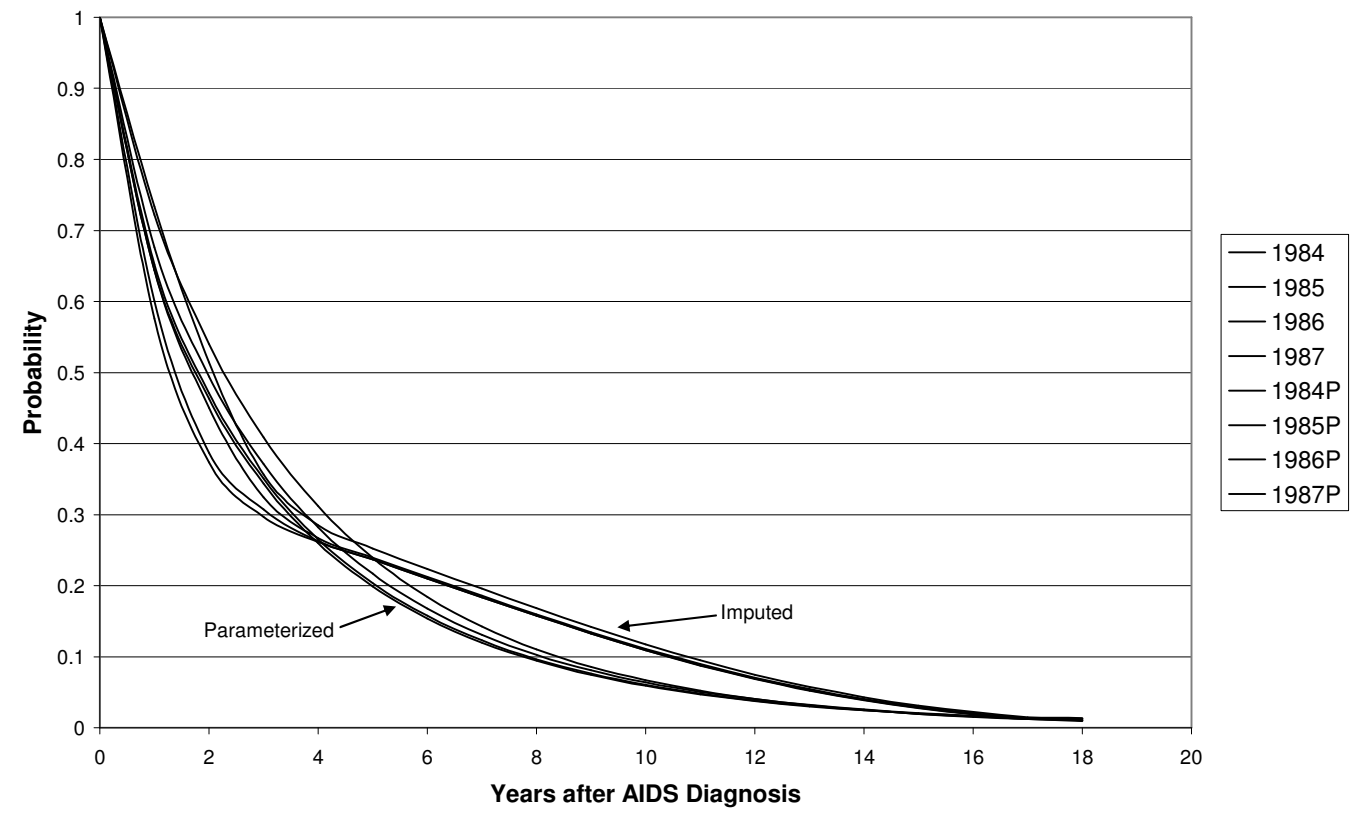

Table 2 presents estimates of life expectancy conditional on a diagnosis of AIDS in a given year. Our estimates suggest that life expectancy has increased from 2.9 years in 1984 to 16.5 years in 2000.

Table 2: Life Expectancy after a Diagnosis of AIDS for Various Years of Diagnosis

\begin{tabular}{cc}
\hline \hline Year & $\begin{array}{c}\text { Life expectancy } \\
\text { conditional on AIDS } \\
\text { Diagnosis }\end{array}$ \\
\hline 1985 & 2.9 \\
1988 & 3.6 \\
1991 & 4.3 \\
1994 & 9.5 \\
1997 & 13.0 \\
1998 & 13.7 \\
1999 & 16.1 \\
2000 & 16.5 \\
\hline \hline
\end{tabular}

These estimates differ somewhat from others in the literature. For example, Lichtenberg estimates life expectancy of an individual diagnosed with 
AIDS in 1993 (2000) to be 3.7 (26.3) years. This might, in part, be due to his period life-table rather than cohort specific approach. In addition, he assumes a constant hazard (mortality rate) - the calculated life expectancy is equal to the inverse of the hazard. A comparison of our year 2000 survival curve with that of Lichtenberg (exponential distribution with hazard $=.038$ ) demonstrates that the two track each other fairly closely for the first 20 years. After that, however, our survival falls off much more rapidly-for example, 30 years after diagnosis, $32 \%$ (as opposed to $11 \%$ ) are still alive in the exponential specification. ${ }^{22}$

To further check the robustness of our results, we use a slightly different specification to project the AIDS survival curves. Specifically, an individual diagnosed with AIDS in 1995 who is still alive 5 years later may expect a survival similar to individuals diagnosed with AIDS in 2000. Similarly, an individual diagnosed with AIDS in 1984 who is alive in 1989 may expect survival similar to an individual of the same age diagnosed in 1989. Fixing the 2000 survival curve to the one calculated before, we can "back-calculate" survival curves for individuals diagnosed in earlier years according to the above algorithm. The life expectancies generated by the 'back-calculation' method are on average 2.2 years longer, with the majority of the differences lying in the later years. Since the magnitude of our results does not depend crucially on this difference, we use the survival curves generated by the imputation method in all subsequent analysis.

\section{Generating Survival Conditional on an Infection with HIV}

We use discrete-time AIDS-free survival $S_{\text {HIV }}(d)$ for an HIV infected individual to obtain the probability distribution function, $\mathrm{f}_{\mathrm{HIV}}(\mathrm{d})$. This distribution states the proportion of individuals who contract AIDS exactly d years after HIV infection. This distribution is allowed to vary by year of HIV infection to capture the delayed progression to AIDS due to antiretroviral treatment. Consider an individual infected with HIV in 1979 . With probability $\mathrm{f}_{\mathrm{HIV}, 79}(1)$, this individual contracts AIDS within the next year and faces the survival curve for an individual diagnosed with AIDS in 1980. Similarly, with probability $\mathrm{f}_{\mathrm{HIV}, 79}(2)$, this individual contracts AIDS exactly two years after infection with HIV and faces

\footnotetext{
${ }^{22}$ To compare the reasonableness of our end-of-life assumptions, we make the following calculation. Suppose that the life expectancy of an individual diagnosed with AIDS in 2000 is, in fact, 26.3 years. Using CDC data on the first 5 years of survival, we can project survival past 5 years using the survival curve of a normal individual of age $Y$. The question we ask is-what age $\mathrm{Y}$ is consistent with an overall AIDS life expectancy of 26.3 years? The answer is $\mathrm{Y}=51$ years. Thus, conditional on being alive five years after a diagnosis of AIDS, instead of assuming the survival of a normal 45 year-old, an AIDS patient assumes the survival of a normal 51 year-old. This implies that for these individuals, AIDS lowers life expectancy by only 4.5 years, which seems too low.
} 
the survival curve for an individual diagnosed with AIDS in 1981. Using this logic, the survival curve for an individual infected with HIV in 1979 is

$$
S_{H I V}^{1979}(d)=f_{H I V}^{1979}(1) \cdot S_{A I D S}^{1980}(d-1)+f_{H I V}^{1980}(1) \cdot S_{A I D S}^{1981}(d-2)+\ldots
$$

which is a weighted average of the survival from AIDS for different years of AIDS diagnosis. Note that the lags in the survival functions account for the fact that the individual has lived several years before contracting AIDS. For years after 2000, we assume that the survival curve for AIDS takes its 2000 value. We use the above metric to generate estimates of survival conditional on an infection with HIV for each year from 1979 to 2000 . These are presented in Table 3 below.

Table 3: Average Time to Onset of AIDS and Life Expectancy after an Infection with HIV for Various Years of Infection

\begin{tabular}{lll}
\hline \hline Year & $\begin{array}{l}\text { Time-to- } \\
\text { AIDS (years) }\end{array}$ & $\begin{array}{l}\text { Life- } \\
\text { Expectancy } \\
\text { (years) }\end{array}$ \\
\hline 1980 & 13.3 & 19.6 \\
1983 & 13.3 & 21.6 \\
1986 & 13.3 & 23.6 \\
1989 & 13.4 & 25.6 \\
1992 & 14.4 & 27.7 \\
1995 & 21.5 & 32.3 \\
1998 & 23.9 & 33.2 \\
2000 & 24.1 & 34.1 \\
\hline \hline
\end{tabular}




\section{References}

Arrow, Kenneth, "Economic Welfare and the Allocation of Research for Invention," in The Rate and Direction of Inventive Activity: Economic and Social Factors," e. R. Nelson, Princeton University Press (1961).

Becker, G.S., Philipson, T.J., Soares, R., "The Quantity and Quality of Life and theEvolution of World Inequality," American Economic Review, 2005, 95, pp. 277-291.

Brookmeyer, R., "Reconstruction and Future Trends of the AIDS Epidemic in the United States," Science, 1991, 253, pp. 37-42.

Collaborative Group on AIDS Incubation and HIV Survival including CASCADE EU Concerted Action, "Time from HIV-1 Seroconversion to AIDS and Death before Widespread Use of Highly-Active Antiretroviral Therapy: A Collaborative Reanalysis,” The Lancet, 2000, 355, pp. 1131-1137.

CASCADE Collaboration, "Determinants of Survival Following HIV-1 Seroconversion after the Introduction of HAART," The Lancet, 2003, 362, pp. 1267-1274.

Caves, R., Whinston, M., Hurwitz, M., "Patent Expiration, Entry, and Competition in the U.S. Pharmaceutical Industry," Brookings Paper on Microeconomic Activity, Microeconomics, 1991, pp. 1-66.

Cutler, D., Your Money or Your Life: Strong Medicine for America's Health Care System, 2004, Oxford University Press, New York, New York.

Cutler, D.M., and Richardson, E., "The Value of Health: 1970-1990," American Economic Review, 1998, 88, pp. 97-100.

Cutler, D.M., and McClellan, M., "Is Technological Change in Medicine Worth It?," Health Affairs, 2001, 20, pp. 11-29.

Duggan, M., and Evans, W., "The Impact of HIV Antiviral Treatments: Evidence for California's Medicaid Population," 2004, Department of Economics Working Paper, University of Maryland. 
Drummond, M.F., O’Brien, B., Stoddart, G.L, and Torrance, G.W., Methods for the Economic Evaluation of Healthcare Programmes, 1997, Oxford University Press, New York, New York.

Goldman, D., Bhattacharya, J., McCaffrey, D., Duan, N., Leibowitz, A., and Morton, S., "The Effect of Insurance on Mortality in an HIV+ Population in Care," Journal of the American Statistical Association, 2001, 96, pp. 883-894.

Bhattacharya, J., Goldman, D., "The Link between Public and Private Insurance and HIV-Related Mortality," Journal of Health Economics, 2003, 22, pp. 1105-1122.

Health, United States; National Center for Health Statistics with Chartbook on Trends in the Health of Americans, Hyattsville, MD, 2002.

Garber, A.M. and Phelps, C.E., "Economic Foundations of Cost-Effectiveness Analysis," Journal of Health Economics, 1997, 16, pp. 1-32.

Garber, A.M., “Advances in Cost-Effectiveness Analysis of Health Interventions," NBER Working Paper 7198 (1999).

Gold, M.R., Siegel, J.E., Russell, L.B., and Weinstein, M.C., Cost-Effectiveness in Health and Medicine, 1996, Oxford University Press, New York, New York.

Hall, B.H., "The Private and Social Returns to Research and Development," Technology, R\&D, and the Economy, ed. B. Smith and C. Barfield, Brookings Institution/American Enterprise Institute, 1996.

Johannesson, M., and Weinstein, M.C., "On the Decision Rules of CostEffectiveness Analysis," Journal of Health Economics, 1993, 12, pp. 459467.

Kates, J., and Wilson, A. "Medicaid \& HIV/AIDS," 2004, Publication 7172, Henry J. Kaiser Family Foundation.

Lichtenberg, F.R., "The Impact of Increased Utilization of HIV Drugs on Longevity and Medical Expenditure: An Assessment Based on Aggregate U.S. Time-Series Data,” 2005, Columbia Business School Working Paper. 
Lee, L.M., Karon, J.M., Selik, R. Neal, J., and Fleming, P., "Survival after AIDS Diagnosis in Adolescents and Adults during the Treatment Era, United States, 1984-1997," Journal of the American Medical Association, 2001, 10, pp. 1308-1315.

Levin, R.C., Klevorick, A.K., Nelson, R.R., Winter, S.G., Gilbert, R., and Griliches, Z., "Appropriating the Returns from Industrial Research and Development," Brookings Papers on Economic Activity, 1987, 3, pp. 783-831.

Mansfield, E., "How Rapidly Does New Technology Leak Out?," The Journal of Industrial Economics, 1985, 34, pp. 217-223.

Mansfield, E., Rapoport, J., Romeo, A., Wagner, S., and Beardsley, G. "Social and Private Rates of Return from Industrial Innovation," The Quarterly Journal of Economics, 1977, 91, pp. 221-240.

Meltzer, D., "Accounting for Future Costs in Medical Cost-Effectiveness Analysis," Journal of Health Economics, 1997, 16, pp. 33-64.

Nordhaus, W.D., "Schumpeterian Profits in the American Economy: Theory and Measurement," NBER Working Paper, 2004.

Phelps, C.E. and Parente, S.T., "Priority Setting in Medical Technology and Medical Practice Assessment," Medical Care, 1990, 28, pp. 703-723.

Philipson, T.J., "Economic Epidemiology and Infectious Disease," Chapter in Handbook of Health Economics. Edited by J. Newhouse and A. Culyer, 2000, Elsevier B.V., North Holland.

Philipson, T.J. and Mechoulan, S., "Intellectual Property and External Consumption Effects: Generalizations from Pharmaceutical Markets," NBER Working Paper, 2003.

Philipson, T.J. and Jena, A.B., "Surplus Appropriation from R\&D and Technology Assessment Procedures," Department of Economics Working Paper, University of Chicago, 2005.

Pharmaceutical Research and Manufacturers of America, PhRMA Annual Membership Survey, 2003. 
Rosenberg, P., Biggar, R., and Goedert, J., "Declining Age at HIV infection in the United States," New England Journal of Medicine, 1994, 330, pp. 789790.

Tirole, Jean. The Theory of Industrial Organization, The MIT Press (1988).

Weinstein, M.C. and Manning, W.G., Jr. "Theoretical Issues in CostEffectiveness Analysis" Journal of Health Economics, 1997, 16, pp. 121128.

Weinstein, M.C. and Stason, W.B., "Foundations of Cost-Effectiveness Analysis for Health and Medical Practices," New England Journal of Medicine, 1977, 296, pp. 716-721. 